\title{
PENGONTROLAN KUALITAS PRODUK MENGGUNAKAN METODE BAGAN KENDALI MULTIVARIAT NP DALAM USAHA PENINGKATAN KUALITAS (STUDI KASUS. CV MULTI REJEKI SELARAS, KOTA PAYAKUMBUH)
}

\author{
SISI ANDRIANI, FERRA YANUAR, YUDIANTRI ASDI \\ Program Studi Matematika, \\ Fakultas Matematika dan Ilmu Pengetahuan Alam, Universitas Andalas, \\ Kampus UNAND Limau Manis Padang, Indonesia, \\ email : sisiandriani94@yahoo.co.id
}

\begin{abstract}
Abstrak. Penelitian ini bertujuan untuk mengidentifikasi karakteristik-karakteristik kecacatan yang mempunyai kontribusi terbesar menyebabkan proses tidak terkendali pada proses produksi air minum Asri di CV. Multi Rejeki Selaras Kota Payakumbuh. Metode yang digunakan dalam penelitian ini adalah metode bagan kendali Multivariat np. Bagan kendali Multivariat np ini biasanya digunakan untuk data cacat. Data yang digunakan adalah data sekunder pada bulan Juni dan Juli tahun 2016 tentang produksi air minum Asri di CV. Multi Rejeki Selaras Kota Payakumbuh. Karakteristik kecacatan yang ditemukan pada produk air minum Asri ini adalah berupa cacat cup, cacat lid, cacat volume, dan sliding mesin. Prosedur untuk membangun bagan kendali Multivariat $n p$ ini terdiri dari dua tahap yaitu tahap start-up stage dan tahap pengendalian proses. Setelah dilakukan identifikasi terhadap karakteristik-karakteristik kecacatan yang mempunyai kontribusi terbesar menyebabkan proses tidak terkendali tersebut dapat diketahui bahwa karakteristik cacat volume merupakan karakteristik yang mempunyai kontribusi terbesar menyebabkan proses tidak terkendali.
\end{abstract}

Kata Kunci: Bagan kendali Multivariat np, karakteristik kecacatan, tahap start-up stage, tahap pengendalian proses

\section{Pendahuluan}

Air merupakan senyawa kimia yang sangat penting bagi kehidupan makhluk hidup di bumi ini. Fungsi air bagi kehidupan tidak dapat digantikan oleh senyawa lain. Air bersih untuk air minum sudah semakin langka. Sungai-sungai yang menjadi sumbernya sudah tercemar berbagai macam limbah, mulai dari buangan sampah organik, rumah tangga hingga limbah beracun dari industri. Air tanah sudah tidak aman dijadikan air minum karena telah terkontaminasi rembesan dari tangki septik maupun air permukaan. Hal inilah yang menjadi alasan mengapa air minum dalam kemasan yang disebut-sebut menggunakan air pegunungan banyak dikonsumsi. Air minum dalam kemasan adalah air yang telah melalui proses sterilisasi, dikemas, dan aman untuk diminum.

Perusahaan CV. Multi Rejeki Selaras merupakan salah satu perusahaan yang memproduksi air minum dalam kemasan. Hasil produksi CV. Multi Rejeki Selaras 
yaitu produk merek Asri. Pada perusahaan CV. Multi Rejeki Selaras, produk yang dihasilkan tidak seluruhnya baik, selalu ada saja produk yang mengalami kecacatan. Banyaknya produk mengalami kecacatan akan menyebabkan proses menjadi tidak terkendali, sehingga produk cacat merupakan permasalahan yang perlu dipecahkan karena apabila tidak diatasi dapat menimbulkan kerugian bagi perusahaan. Untuk mencegah kerugian karena produk cacat maka dilakukan pengendalian kualitas supaya proses berada dalam keadaan terkendali. Dengan demikian sangatlah penting dilakukan pengidentifikasian terhadap karakteristik-karakteristik kecacatan yang mempunyai kontribusi terbesar yang menyebabkan proses tidak terkendali. Untuk mencapai tujuan tersebut salah satu cara yang dilakukan adalah dengan membuat bagan kendali. Bagan kendali yang sesuai dengan kasus ini adalah bagan kendali Multivariat $n p$ karena jenis karakteristik cacat yang terdapat pada produk Asri ini lebih dari satu.

\section{Bagan Kendali Multivariat $n p$}

Karakteristik multivariat adalah pemeriksaan obyek yang dilakukan pada lebih dari satu karakteristik kualitas. Bagan kendali Multivariat $n p$ merupakan bagan kendali multivariat atribut yang digunakan untuk mengevaluasi kualitas berdasarkan proporsi cacat dengan jenis cacat jumlahnya lebih dari satu. Sehingga apabila proses mempunyai karakteristik multivariat dan bersifat atribut maka bagan kendali yang paling cocok digunakan adalah bagan kendali Multivariat $n p$.

Prosedur untuk membangun bagan kendali Multivariat $n p$ ini terdiri dari dua tahap, yaitu tahap start-up stage dan tahap pengendalian proses. Berikut akan diuraikan langkah-langkah untuk pembuatan bagan kendali pada masing-masing tahap.

\subsection{Tahap Start-Up Stage}

Langkah-langkah yang dilakukan pada tahap start-up stage ini adalah sebagai berikut:

(1) Mengestimasi Parameter.

Langkah-langkah untuk menaksir parameter tersebut adalah sebagai berikut:

(a) Mengambil sebanyak $k$ pengamatan dengan ukuran sampel untuk setiap pengamatan adalah $n$.

(b) Menentukan banyaknya produk yang cacat untuk setiap karakteristik pada masing-masing pengamatan, dimisalkan dengan $c_{j i}$, dengan $j=1,2, \cdots, k$ dan $i=1,2, \cdots, m$, dimana $k$ menyatakan banyaknya pengamatan dan $m$ menyatakan banyaknya karakteristik.

(c) Menghitung $p_{j i}$ dengan rumusan berikut.

$$
p_{j i}=\frac{c_{j i}}{n} .
$$

(d) Menghitung nilai rata-rata proporsi produk cacat untuk semua pengamatan berdasarkan karakteristik kualitas, dilambangkan dengan $\overline{p_{i}}$ dengan 
rumusan berikut.

$$
\overline{p_{i}}=\frac{\sum_{j=1}^{k} p_{j i}}{k}=\frac{\sum_{j=1}^{k} c_{j i}}{n k} .
$$

Selanjutnya akan dicari nilai koefisien korelasi antar karakteristik. dilambangkan dengan $r_{C_{i} C_{i}^{*}}$. Lu membuat catatan untuk koefisien korelasi ini sebagai berikut.

$$
\begin{aligned}
r_{C_{i} C_{i^{*}}} & =r_{C_{i^{*}} C_{i}}, \\
\left|r_{C_{i} C_{i^{*}}}\right| & \leq 1, \\
r_{C_{i} C_{i^{*}}} & =1, \text { jika } i=i^{*} .
\end{aligned}
$$

Formula untuk mengestimasi korelasi tersebut adalah sebagai berikut:

$$
r_{C_{i} C_{i^{*}}}=\frac{k \sum_{j=1}^{k} c_{j i} c_{j i^{*}}-\left(\sum_{j=1}^{k} c_{j i}\right)\left(\sum_{j=1}^{k} c_{j i^{*}}\right)}{\sqrt{\left(n \sum_{j=1}^{k} c_{j i}^{2}-\left(\sum_{j=1}^{k} c_{j i}\right)^{2}\right)\left(n \sum_{j=1}^{k} c_{j i^{*}}{ }^{2}-\left(\sum_{j=1}^{k} c_{j i^{*}}\right)^{2}\right)}} .
$$

(2) Menentukan Nilai Statistik $X$.

Statistik $X$ tersebut merupakan transformasi dari data untuk kemudian diplot pada bagan kendali Multivariat $n p$. Apabila terdapat pengamatan sebanyak $j=1,2, \cdots, k$ maka nilai statistik $X$ pada setiap pengamatan adalah:

$$
X_{j}=\sum_{i=1}^{m} \frac{c_{j i}}{\sqrt{p_{i}}}, j=1,2, \cdots, k .
$$

(3) Menentukan Batas Kendali.

Batas kendali pada tahap ini dapat dihitung dengan menggunakan rumusan berikut:

$$
\begin{aligned}
& B K A=n \sum_{i=1}^{m} \sqrt{\overline{p_{i}}}+3 \sqrt{n\left(\sum_{i=1}^{m}\left(1-\overline{p_{i}}\right)+2 \sum_{i<i^{*}} r_{c_{i} c_{i^{*}}} \sqrt{\left(1-\overline{p_{i}}\right)\left(1-\overline{p_{i^{*}}}\right)}\right)}, \\
& G T=n \sum_{i=1}^{m} \sqrt{\overline{p_{i}}}, \\
& B K B=n \sum_{i=1}^{m} \sqrt{\overline{p_{i}}}-3 \sqrt{n\left(\sum_{i=1}^{m}\left(1-\overline{p_{i}}\right)+2 \sum_{i<i^{*}} r_{c_{i} c_{i^{*}}} \sqrt{\left(1-\overline{p_{i}}\right)\left(1-\overline{p_{i^{*}}}\right)}\right)} .
\end{aligned}
$$

\subsection{Tahap Pengendalian Proses}

Langkah-langkah yang dilakukan pada tahap pengendalian proses ini adalah sebagai berikut.

(1) Menghitung Nilai Statistik $X$.

Formula untuk menghitung nilai statistik $X$ pada tahap ini sama dengan pada tahap sebelumnya.

(2) Menentukan Batas Kendali.

Batas kendali yang digunakan pada tahap ini adalah batas kendali yang sudah terkendali yang dihasilkan pada tahap start-up stage. Selanjutnya lakukan plot 
164 Sisi Andriani dkk.

nilai statistik $X$ yang telah diperoleh pada bagian (1) di atas dengan batas kendali tersebut.

(3) Mengidentifikasi Karakteristik Penyebab Pengamatan Tidak Terkendali.

Statistik yang digunakan dalam menginterpretasikan proses di luar kendali dalam bagan kendali Multivariat $n p$ adalah dengan menghitung skor statistik pada setiap karakteristik kualitas ke- $i$ yang berada di luar batas kendali, $Z_{i}$, dengan menggunakan formula berikut.

$$
Z_{i}=\frac{\left[C_{j i}-n \overline{p_{i}}\right]}{\sqrt{\overline{p_{i}}}} .
$$

\section{Data dan Pembahasan}

Prosedur untuk membangun bagan kendali Multivariat $n p$ ini terdiri dari dua tahap yaitu sebagai berikut.

\subsection{Penerapan Bagan Kendali Multivariat np pada Tahap Start-Up Stage}

Pada pengontrolan produksi pahap start-up stage, langkah awal yang dilakukan adalah menghitung nilai korelasi antar karakteristik. Pada Tabel 1 diberikan nilai korelasi untuk semua karakteristik.

Tabel 1. Nilai Korelasi untuk semua karakteristik

\begin{tabular}{|c|c|}
\hline Karakteristik & Korelasi \\
\hline$C_{1} \operatorname{dan} C_{2}$ & 0,407 \\
\hline$C_{1} \operatorname{dan} C_{3}$ & 0,462 \\
\hline$C_{1} \operatorname{dan} C_{4}$ & 0,241 \\
\hline$C_{2} \operatorname{dan} C_{3}$ & 0,526 \\
\hline$C_{2} \operatorname{dan} C_{4}$ & 0,233 \\
\hline$C_{3} \operatorname{dan} C_{4}$ & 0,575 \\
\hline
\end{tabular}

Langkah selanjutnya adalah menghitung rata-rata proporsi produk cacat. Pada Tabel 2 diberikan hasil rata-rata proporsi produk cacat.

Tabel 2. Rata-rata proporsi produk cacat

\begin{tabular}{|c|c|}
\hline$\overline{p_{i}}$ & Nilai \\
\hline$\overline{p_{1}}$ & 0,000738 \\
\hline$\overline{p_{2}}$ & 0,000755 \\
\hline$\overline{p_{3}}$ & 0,000721 \\
\hline$\overline{p_{4}}$ & 0,000758 \\
\hline
\end{tabular}

Setelah diketahui estimasi dari rata-rata proporsi produk cacat $\overline{p_{i}}$ dan estimasi 
matriks korelasi, maka selanjutnya adalah menentukan batas kendali sehingga diperoleh $B K A=4819,684, G T=3271,143$, dan $B K B=1722,602$. Langkah selanjutnya adalah mencari nilai statistik $X$. Setelah diperoleh batas-batas kendali dan nilai-nilai nstatistik $X$, maka langkah selanjutnya adalah memplotkan nilai-nilai statistik $X$ dengan batas kendalinya. Pada Gambar 1 diberikan hasil plot statistik $X$ dengan batas kendalinya.

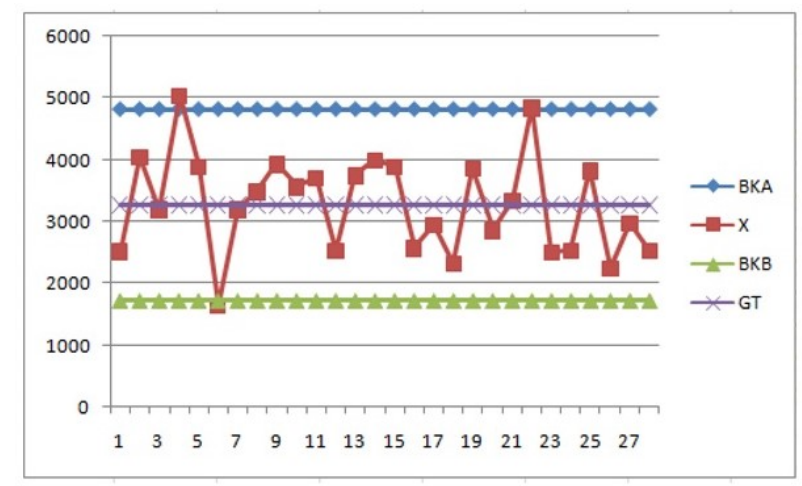

Gambar 1. Hasil plot statistik $X$ dengan batas kendalinya

Dari bagan kendali pada Gambar 1 terlihat bahwa ada tiga pengamatan yang berada di luar batas kendali sehingga perlu dilakukan perhitungan ulang dan diperoleh batas kendali yang baru yaitu $B K A=4601,931, G T=3236,917$, dan $B K B=1871,902$. Dan juga dicari nilai statistik $X$ yang baru. Setelah itu dibuat plot antara nilai statistik $X$ dengan batas kendalinya. Pada Gambar 2 diberikan plot statistik $X_{\text {baru }}$ dengan batas kendalinya.

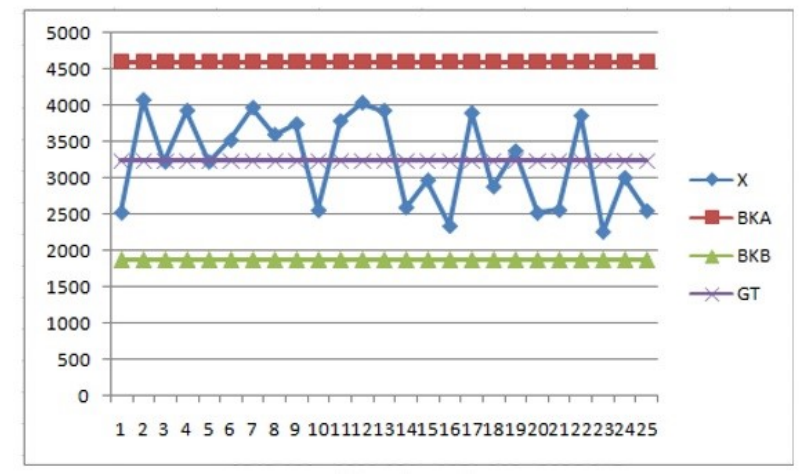

Gambar 2. Hasil plot statistik $X$ dengan batas kendalinya

Dari hasil plot pada Gambar 2 terlihat bahwa semua pengamatan berada dalam batas kendali sehingga batas kendali pada tahap ini dapat digunakan untuk batas 
kendali pada tahap pengendalian proses.

\subsection{Penerapan Bagan Kendali Multivariat np pada Tahap Pengendalian Proses}

Batas kendali yang digunakan pada tahap ini adalah batas kendali yang sudah terkendali pada tahap start-up stage. Selanjutnya adalah menghitung nilai statistik $X$. Langkah selanjutnya adalah memplotkan nilai statistik $X$ dengan batas kendali. Pada Gambar 3 diberikan hasil plot antara nilai statistik $X$ dengan batas kendalinya.

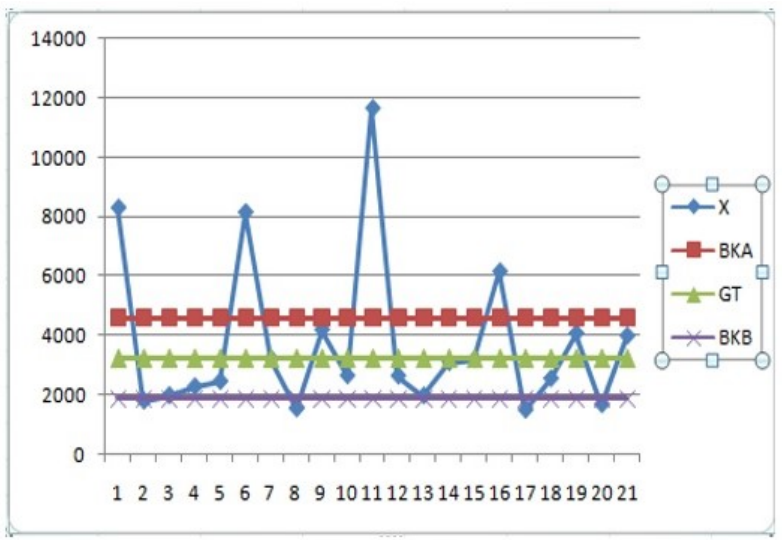

Gambar 3. Plot antara nilai statistik $X$ dengan batas kendalinya

Dari hasil plot pada Gambar 3 terlihat bahwa terdapat delapan pengamatan yang berada di luar batas kendali. Hal ini menunjukkan bahwa kualitas produksi air minum Asri dalam kemasan $240 \mathrm{ml}$ di CV. Multi Rejeki Selaras Payakumbuh belum stabil. Selanjutnya akan ditelusuri karakteristik mana saja yang berperan paling tinggi menyebabkan proses tidak terkendali. Dalam bagan kendali Multivariat $n p$, untuk mengidentifikasi proses yang berada di luar batas kendali dari pengamatan dengan cara menghitung statistik $Z_{i}$ untuk setiap karakteristik pada setiap pengamatan yang berada diluar batas kendali. Hasil perhitungan nilai statistik $Z_{i}$ untuk semua pengamatan yang berada di luar batas kendali ini kemudian dirangkum dalam Tabel 3 .

Dari Tabel 3 dapat diketahui bahwa yang merupakan kontribusi terbesar yang menyebabkan proses di luar kendali adalah karakteristik ke-3 yaitu karakteristik cacat volume.

\section{Ucapan Terima Kasih}

Penulis mengucapkan terima kasih kepada Ibu Hazmira Yozza, Bapak Ahmad Iqbal Baqi, dan Ibu Lyra Yulianti yang telah memberikan masukan dan saran sehingga paper ini dapat diselesaikan dengan baik. 
Tabel 3. Karakteristik pengamatan di luar batas kendali

\begin{tabular}{|c|c|c|c|c|}
\hline \multirow{2}{*}{ Pengamatan } & \multicolumn{4}{|c|}{ Karakteristik } \\
\cline { 2 - 5 } & 1 & 2 & 3 & 4 \\
\hline \hline 1 & 2482,079 & 1151,427 & 692,8891 & 206,5944 \\
\hline 2 & $-630,024$ & $-450,331$ & $-604,912$ & $-279,091$ \\
\hline 6 & 155,3997 & 966,6124 & 2503,184 & 756,9989 \\
\hline 8 & $-720,882$ & $-573,514$ & $-365,963$ & $-570,447$ \\
\hline 11 & 2028,829 & 2414,331 & 2264,088 & 1177,896 \\
\hline 16 & $-479,149$ & 1644,268 & 146,385 & 1080,766 \\
\hline 17 & $-539,582$ & $-604,316$ & $-878,310$ & $-246,680$ \\
\hline 20 & $-509,366$ & $-450,303$ & $-195,180$ & $-926,591$ \\
\hline
\end{tabular}

\section{Daftar Pustaka}

[1] Johnson, A.R. dan D.W. Wichern. 2002. Applied Multivariate Statistical Analysis. $5^{\text {th }}$ ed. Prentice Hall, Upper Saddle River, New Jersey.

[2] Lu, X. S, et al. 1998. Control Chart for Multivariate Atribute Processes. International Journal of Production Research 36(12) : 3477 - 3489.

[3] Montgomery, D.C. 2001. Introduction to Statistical Quality Control , $4^{\text {th }}$ ed. John Wiley and Sons, Inc., New York.

[4] Montgomery, D.C. 2005. Introduction to Statistical Quality Control, $5^{\text {th }}$ ed. John Wiley and Sons, Inc., New York.

[5] Walpole, R. E. 1995. Pengantar Statistik. Edisi Ketiga. PT. Gramedia Pustaka Umum, Jakarta. 